\title{
CONTRIBUCIONES DEL PSICOANÁLISIS LACANIANO A LA TEORÍA POLÍTICA Y SOCIAL CONTEMPORÁNEA Y AL ANÁLISIS SOCIOPOLIITICO CRIITICO
}

\author{
CONTRIBUTIONS FROM THE LACANIAN PSYCHOANALYSIS \\ TO THE CONTEMPORARY SOCIAL AND POLITICAL THEORY \\ AND THE CRITICAL SOCIOPOLITICAL ANALYSIS
}

\section{Hernán Fair*}

RESUMEN

El artículo analiza algunas contribuciones teóricas relevantes del psicoanálisis lacaniano a las Ciencias Sociales y Humanísticas. Específicamente, hace hincapié en algunos de sus principales aportes e implicancias para el desarrollo de la teoría política y social contemporánea, así como, al análisis sociopolítico crítico.

PALABRAS CLAVE: LACAN * PSICOANÁLISIS * TEORÍA SOCIAL * TEORÍA POLÍTICA * ANÁLISIS SOCIOPOLÍTICO * IZQUIERDA LACANIANA

\section{ABSTRACT}

This article analyzes some relevant theoretical contributions from the Lacanian psychoanalysis to the Social Sciences and Humanities. Specifically, it emphasized its main theoretical contributions and implications for the development of the contemporary social and political theory and critical sociopolitical analysis.

KEY WORDS: LACAN * PSYCHOANALYSIS * SOCIAL THEORY * POLITICAL THEORY * SOCIOPOLITICAL ANALYSIS * LACANIAN LEFT

1 Una versión anterior de este trabajo fue presentado en las IX Jornadas de Sociología "Capitalismo del siglo XXI, crisis y reconfiguraciones. Luces y sombras en América Latina”, Carrera de Sociología, Facultad de Ciencias Sociales, Universidad de Buenos Aires (UBA), Ciudad de Buenos Aires, 8 al 12 de agosto de 2011. Agradezco al evaluador anónimo de esta revista por sus pertinentes sugerencias y comentarios.

* Universidad de Buenos Aires (UBA), Argentina. herfair@hotmail.com / fairhernan@gmail.com 


\section{INTRODUCCIÓN ${ }^{2}$}

Mucho se ha escrito en las últimas décadas acerca de la teoría psicoanalítica del célebre y polémico pensador francés Jacques Lacan. Sin embargo, como señalaba hace unos años Ernesto Laclau (1992), en el prólogo de la obra de Slavoj Zizek, El sublime objeto de la ideología, la mayoría de los trabajos, con excepciones como la denominada Escuela psicoanalítica eslovena, liderada precisamente por el renombrado filósofo y psicoanalista esloveno, han centrado históricamente su interés en su aspecto puramente clínico.

$2 \quad$ Se enfatiza que se trata de algunas contribuciones y no del conjunto, más aún cuando una parte de la compleja y extensa obra de Lacan permanece aún inédita. Además, cabe destacar que el "legado" de esas contribuciones nunca está dado de antemano, ni debe ser entendido como el desarrollo de "la" verdadera teoría lacaniana, sino que es producto de una interpretación puramente personal, consecuencia de una serie de lecturas también personales y selectivas. Además, se debe destacar las valiosas contribuciones $y$ aportes que he recibido ( $y$ de las que soy deudor) de trabajos que han aplicado empíricamente al análisis político algunas categorías provenientes del psicoanálisis lacaniano, como los de Biglieri (2006) y Gómez (2006), así como de las clases en el Doctorado de la UBA y las diversas conversaciones e intercambios personales y electrónicos que he tenido con algunos referentes que he mencionado, incluyendo académicos, profesores y analistas provenientes, tanto del campo del psicoanálisis como también de la teoría política, así como, otros aportes de colegas cuya lista sería difícil de sintetizar, pero que me han ayudado, en estos años, a intentar comprender al menos una parte de la (tal vez alevosamente) intrincada y compleja, pero a la vez fascinante $y$ estimulante, teoría psicoanalítica lacaniana. En muchos casos, estos colegas y analistas me han alentado a continuar en esta disputa hegemónica tendiente a destacar las contribuciones que puede brindarnos la teoría psicoanalítica al análisis sociopolítico crítico. Por último, quisiera destacar que la selección de exégetas y referencias clave que he mencionado, no implica olvidar los aportes de otras referencias académicas habitualmente consideradas más "relevantes" (Louis Althusser, Elizabeth Roudinesco, Jacques Alain Miller, Eric Laurent, Jean Claude Milner, entre tantos otros), pero es por ello que he enfatizado que este trabajo condensa una interpretación personal, producto de las lecturas, interacciones e influencias propias, lo que pudiera o no ser compartido por otros exégetas del pensamiento lacaniano.
En ese marco, han dejado en un lugar relegado su indudable acercamiento a las ciencias sociales y humanísticas. Se ha pretendido olvidar, en ese sentido, que el propio Lacan, además de ser un asiduo lector de la filosofía, incluía, entre sus trabajos y escritos, una pluralidad de citas referidas a pensadores externos al campo psicoanalítico, o incluso al psicológico. Así, se pueden observar diversas menciones, algunas más habituales que otras, a la filosofía antigua (Aristóteles y Platón) y moderna (Kant, Hegel, Descartes, Marx y Wittgenstein), a la lingüística (De Saussure), a la semiótica social (Peirce), a la epistemología crítica (Quine, Frege, Godel y Lakatos), e incluso a la filosofía china (Tao). Además, numerosos autores han destacado la influencia que ha ejercido sobre su obra el pensamiento de filósofos contemporáneos de la importancia de Levi Strauss, Merleau Ponty, Heidegger, Nietzsche, Foucault, Sartre y Kojeve, o lingüistas como Benveniste y Jacobson, a pesar de que el propio Lacan pudiera no citarlos de manera explícita. Cabe mencionar, a su vez, que el propio Lacan, especialmente en sus últimos seminarios, ha desarrollado un tipo de análisis interdisciplinario, en confluencia con varios de los temas más relevantes relacionados a la teoría política y social y al análisis sociopolítico crítico ${ }^{3}$.

3 En ese marco, este artículo responde a un conjunto de lecturas autodidactas que incluyen varios de los más importantes escritos y seminarios del propio Lacan en diversas etapas de su obra. Además, debo reconocer los indudables aportes que he recibido de algunos de los principales seguidores y referentes de la teoría y el pensamiento político "posfundacional" (entre los más destacados, Zizek, Stavrakakis, Alemán, Badiou y Laclau), quienes promueven diversas vinculaciones entre el psicoanálisis y lo político (en sentido amplio). En dicho contexto, además, me he enriquecido notablemente $y$ he aprendido mucho, con la lectura de exégetas que han analizado diversos aspectos de su obra, como su teoría de los discursos sociales (Álvarez, 2006), la teoría de los conjuntos y sus relaciones con la política (Badiou, 2007), el concepto lacaniano de goce (Braunstein, 2006), las relaciones con la epistemología post-racionalista (Alemán, 2010), el pensamiento de Heidegger (Alemán, 1993), la dialéctica hegeliana y el kantismo (Zizek, 1992 y 2003), la semiótica social (Rome, 2009) y la lingüística (Dor, 1997), o bien han desarrollado los 
Así, aunque las intersecciones entre el psicoanálisis, lo político y lo social se encuentran presentes ya desde sus primeros seminarios y escritos, continuando con la idea freudiana de que toda psicología individual representa también una psicología social (Freud, 1979), es especialmente a partir de su seminario XVII, "El reverso del psicoanálisis", conocido corrientemente como el seminario sobre los "Cuatro discursos", donde el teórico $y$ analista francés ha incursionado de manera definitiva, aunque muchas veces sutil, en los temas filosófico-político-sociales-culturales. En ese contexto, aunque siempre más interesado en los efectos derivados en el plano individual del sujeto ${ }^{4}$, Lacan (2006) ha criticado, en la misma línea que una parte de la teoría y filosofía política y social moderna (Rousseau, 1996),

principales vínculos existentes entre la teoría y filosofía política y el análisis sociopolítico crítico y el psicoanálisis lacaniano (Stavrakakis, 2008 y 2010; Alemán, 2010), hallando algunas similitudes y afinidades entre sus categorías y la teoría política contemporánea (Zizek, 1992, 2001, 2003 y 2006; Laclau, 2003 y 2005; Lebrún, 2003; Copjec, 2006). En todo caso, conscientes de que existe una pluralidad de interpretaciones diferentes sobre el psicoanálisis lacaniano, en este ensayo nos situamos (me sitúo) en un "marco teórico" que ha dado en llamarse, de manera arbitraria, la "izquierda lacaniana" (Alemán, 2010; Stavrakakis, 2010), con una orientación más o menos definible a favor de las vinculaciones entre el psicoanálisis lacaniano, la teoría política y social y el análisis sociopolítico crítico, desde una posición en defensa explícita de una democracia ( $y$ un énfasis normativo en la democratización) "radical y plural" (Laclau y Mouffe, 1987).

Cabe aclarar que cuando hace referencia a la teoría política y social, lo hace en un sentido amplio, incluyendo, en ese sentido, a la filosofía política $y$ social, al entender que toda teoría política representa, a su vez, o se encuentra íntimamente ligada (pese a poder diferenciarse y adquirir una "autonomía relativa"), a una determinada teoría social y a una determinada filosofía política y social. Del mismo modo, toda sociología política se inserta también en el marco de una determinada teoría política y social (o de una determinada teoría política que constituye a lo social), en tanto la política, a través del discurso político, es el elemento que, desde el enfoque que seguimos aquí (y que comparte el psicoanálisis lacaniano), constituye imaginariamente el lazo social. así como la contemporánea (Heidegger, 1991), los enfoques críticos (Adorno y Horkheimer, 2002) y posmodernos (Lipovetsky, 2000) y la teoría política, social y cultural (Bauman, 2003, 2007), la primacía que adquiere la lógica del consumo masivo y el hipermercantilismo en la sociedad capitalista. En la misma línea, ha criticado también, en consonancia con la teoría crítica de la Escuela de Frankfurt (Marcuse, 1983; Adorno y Horkheimer, 2002), la sociología cultural (Bourdieu, 1984), la teoría y filosofía política post-estructuralista (Laclau y Mouffe, 1987; Laclau, 1996 y Ranciere, 1996), el análisis semiótico del discurso de origen peirciano (Verón, 1987) y los enfoques filosóficos posmodernos (Lyotard, 1992) y de pensamiento complejo (Morin, 1998), la modalidad de estructuración y legitimación política que presenta el discurso de la Ciencia tradicional, rechazada por intentar borrar la presencia del sujeto $y$ sus elementos de subjetividad inherentes, en pos de una Ciencia posicionada como puramente objetiva y neutral.

Finalmente, desde sus primeros escritos, Lacan (1982, 1987 y 2003) ha destacado la primacía que adquiere el lenguaje como un elemento material que contribuye a conformar $y$ a modificar al sujeto, las identidades $y$ creencias subjetivas, en un aporte conceptual que encuentra afinidades con enfoques como la filosofía analítica (Wittgenstein, 1987), el pragmatismo anglosajón (Austin, 1998), la semiótica social (Pierce, 1955 y Benveniste, 1989) y el postestructuralismo (Laclau y Mouffe, 1987; Derrida, 1989). Sin embargo, donde se puede observar con más detalle esta confluencia posible con la teoría filosófica de la política y el análisis político, social y cultural, es en sus últimos seminarios, especialmente el XIX y el XX. En aquellos seminarios, conocidos como O peor y Aun, el psicoanalista francés desarrolla un análisis teórico que encuentra afinidades directas con la teoría y la sociología política "posfundacional" (Marchart, 2009), e incluso con la epistemología crítica. En ese contexto, se remonta a las contribuciones iniciales de Descartes, para criticar, desde los aportes de la semiótica peirciana, la filosofía analítica del "segundo" Wittgenstein y la epistemología post-racionalista de Quine, Frege, 
Godel, Lakatos y Feyerabend, el tipo de discurso objetivista y cientificista que tiene su origen en la lógica formal aristotélica, la geometría de Euclides y el empirismo leibniziano, hasta alcanzar su elixir con el positivismo lógico y el conductismo anglosajón (Lacan, 1971-1972 y 2008). Al mismo tiempo, en estos y otros seminarios, así como en textos (Lacan, 2005, 2006), el célebre pensador francés se opone con fuerza a la fe positivista en el progreso y el avance de la Ciencia como emancipadoras del hombre, $y$ en la propia fe en el hombre como elemento emancipador, ya sea a través de la clase, el partido, la administración, o cualquier otro elemento sustituto que cumpla esa función, en una crítica anti-positivista que incluye desde Hegel y el marxismo, hasta el positivismo racionalista y el empirismo conductista.

Es, precisamente, a partir del reconocimiento de estas afinidades y diálogos potenciales entre el psicoanálisis lacaniano y los temas circundantes de la teoría política y social contemporánea ${ }^{5}$, en donde, a nuestro entender,

5 A fin de cuentas, el psicoanálisis se aplica sobre pacientes individuales, aunque sabemos que el individuo nunca es plenamente un individuo aislado, sino un ser social atravesado por la sociedad y la cultura, como efecto del lenguaje (Lacan lo define, a partir de Heidegger, como un "ser que habla"). De allí que el psicoanálisis no pueda desatenderse nunca de lo cultural y de lo social, que lo sobredeterminan ya desde el nacimiento (con la imposición de un nombre). En ese marco, el único comentario metodológico que se dirá al respecto, es que los aportes teóricos de Lacan en términos similares o confluentes con la teoría política y social contemporánea, en particular en su Seminario XVII, se enmarcan originariamente en un discurso analítico que, aunque comparte ampliamente los principales presupuestos teóricos y epistemológicos de la teoría política contemporánea que se retoma en este trabajo, parten de la base de las relaciones sociales en términos predominantemente individuales. No obstante, como se verá, Lacan (2006) luego extiende y dialectiza la misma lógica de la "diferencia ontológica" (Marchart, 2009), al conjunto de los discursos existentes (Discurso del Capitalismo, del Amo antiguo, del Universitario, de la Histérica y del Analista). En ese contexto, que permite dilucidar sus fructíferos aportes a la teoría y la filosofía política y al análisis sociopolítico contemporáneo (Stavrakakis, 2008: 17 y ss.), su crítica principal se dirige hacia los enfoques de la "psicología científica" (entre ellas, pueden situarse (es decir, construirse y articularse) los principales aportes de su extensa obra a las ciencias sociales en general, así como a la teoría y el análisis político crítico en particular. Lejos de desconocer que el objetivo central del psicoanálisis lacaniano y del psicoanálisis en general, se vincula a una interpretación crítica tendiente a la emancipación del sujeto en un plano más cercano a lo individual, interesa examinar las posibles aplicaciones e implicancias de sus categorías analíticas para el desarrollo de una ciencia social ( $y$ en especial, una ciencia política) más compleja y con mayor capacidad crítica.

En ese contexto, el objetivo principal no consiste en "hallar" posibles afinidades o similitudes entre el enfoque lacaniano y la teoría política, ni tampoco consiste en indagar en los aportes de las ciencias sociales y humanas a la teoría psicoanalítica, sino en intentar examinar el sentido inverso, analizando algunas de las contribuciones teóricas que pueden derivarse de la obra del célebre psicoanalista francés, al campo de lo político (en sentido amplio) ${ }^{6}$. Específicamente, se procura hacer hincapié en lo que se considera que constituyen algunas de las principales herramientas que puede brindarnos el psicoanálisis lacaniano para el desarrollo y expansión de la teoría política y social, así como al análisis sociopolítico crítico. Como cientistas sociales, se espera en definitiva, acercarse al cumplimiento de dos objetivos "trascendentales". En primer lugar, contribuir a promover $y$ fomentar el análisis multi e interdisciplinario o transdisciplinario, que permita

las neurociencias, el conductismo, la psicología "evolutiva" y la psicología cognitiva), cosmovisiones racionalistas que, al igual que las diversas filosofías ontológicas que nacen en la Antigüedad, y se desarrollan con el capitalismo moderno, rechazan el deseo inconsciente $y$ por lo tanto, la relevancia que adquiere el lenguaje, el sujeto y la alteridad, además de creer en una ciencia objetiva que, a partir del supuesto saber superior del clínico, se basa en la hipermedicalización experimental sobre el "sujeto". Acerca de los "interlocutores" principales a los que se enfrenta Lacan, véase Ramírez Escobar (2009).

6 También sus indudables aportes a la epistemología, desarrollados por autores como Badiou (2007) y Alemán (2010). 
una mayor complejización de aquello que definimos como lo social. En segundo término, de manera simultánea, aportar algunos elementos teóricos que contribuyan a la construcción, desarrollo y expansión de una "izquierda lacaniana” (Alemán, 2010 y Stavrakakis, 2010) que recupere la función política de crítica radical y transformación de las condiciones existentes, promoviendo una mayor democratización en todos los campos del quehacer humano y la extensión normativa de una sociedad más justa, digna, libre, igualitaria y solidaria.

Para intentar llevar a cabo esta tarea, en este artículo se examinarán seis importantes contribuciones que, desde nuestro punto de vista, puede ofrecernos la teoría psicoanalítica lacaniana para el desarrollo y expansión de la teoría y el análisis político y social contemporáneo: 1) La presencia del inconsciente estructurado como un lenguaje, lo que se vincula a la primacía que adquiere el significante para la conformación del sujeto y del lazo social, así como, la recuperación de la retórica, a partir de la metáfora y la metonimia, 2) La afirmación acerca de la "imposibilidad" de la "relación sexual", lo que se relaciona a la lógica teóricopolítica y epistemológica del "no todo", 3) La identificación en torno al denominado "objeto a", vinculado a la construcción parcial del lazo social, 4) La teoría de los tres registros (RSI), relacionada a la presencia del nudo borromeo como una nueva configuración que estructura/ desestructura lo que denominamos lo social, 5) La denominada Teoría de los Cuatro Discursos, que permite comprender diversas modalidades de estructurar discursivamente el lazo social y 6) La importancia del "goce" y el "plus de goce", en tanto elemento primordial que sobredetermina la conformación de la subjetividad.

A continuación, se analizará, de un modo sintético, estos seis aportes teóricos. En ese marco, para enriquecer y promover el diálogo fecundo y contribuir a una mayor y mejor comprensión de nuestro "objeto", se ha decidido incorporar un apartado derivado de cada contribución, que coloca el eje en lo que se aprecia que constituyen las principales implicancias derivadas del enfoque lacaniano para la expansión y el desarrollo de la teoría política y social crítica, en particular, para el análisis sociopolítico posfundacional y de "izquierda lacaniana”. En algunos casos, se han agregado, además, algunas implicancias epistemológicas, pretendiendo contribuir, nuevamente, a una mayor comprensión de los múltiples e incalculables aportes que sin dudas, brindan las herramientas provenientes de la teoría psicoanalítica lacaniana?

\section{SEIS CONTRIBUCIONES DEL PSICOANÁLISIS LACANIANO A LA TEORÍA POLÍTICA Y SOCIAL CONTEMPORÁNEA Y AL ANÁLISIS SOCIOPOLÍTICO CRÍTICO ${ }^{8}$}

\subsection{EL INCONSCIENTE ESTRUCTURADO COMO UN LENGUAJE}

Sigmund Freud, inventor y máximo símbolo del psicoanálisis y de su método interpretativo, fue el primero en subrayar la relevancia clave $y$ fundamental que adquiere el elemento inconsciente en la práctica individual e incluso,

$7 \quad$ Esta recuperación de las contribuciones de la obra de Lacan no debe llevar, sin embargo, a un "endiosamiento" doctrinario y dogmático que impida la crítica sobre sus postulados teóricos. El propio Lacan parece advertirnos que no lo tomemos tan en serio, cuando hace hincapié en lo "barrado" de todo discurso, aunque se debe reconocer que muchos de sus seguidores, comenzando por su principal "heredero", Jacques Alain Miller, fundador de la Asociación Mundial de Psicoanálisis y dueño de los derechos de edición de los Seminarios de Lacan (algunos de ellos, todavía no autorizados por el propio Miller para su edición pública), han generado a un Lacan-Dios, como hay también un Dios Marx, que no admite críticas y debates sobre su enseñanza. Sobre la experiencia de este dogmatismo en el caso argentino, centrado especialmente en la Escuela de Orientación Lacaniana (EOL), véase Vainer (1997).

8 Se reitera que se trata solo de algunas contribuciones e implicancias que pueden derivarse de su obra, así como de una interpretación posible, entre otras igualmente válidas. Además, se debe destacar que las contribuciones teóricas que se plantean en este trabajo se encuentran, en su mayoría, interrelacionadas entre sí, por lo que no deben ser entendidas con independencia unas de otras. En ese marco, la distinción propuesta es meramente analítica $y$ ordenadora. 
como en sus textos llamados "sociales" ${ }^{9}$, en la práctica colectiva de los sujetos. Precisamente, el psicoanálisis se centra en la interpretación del inconsciente de los sujetos, situación que se manifiesta simbólicamente en los sueños, lapsus, actos fallidos y chistes (Freud, 1973a, 1973b y 1979).

Lacan, como continuador crítico de las enseñanzas iniciales de Freud, destacará la relevancia fundamental que adquiere el deseo inconsciente, aunque realizará importantes reformulaciones, en muchos casos, contra los propios presupuestos de su "maestro". Una de las más importantes es la afirmación de que el inconsciente "se estructura como un lenguaje”. ¿Qué significa esto? Significa, a grandes rasgos, que el deseo inconsciente se constituye $y$ se manifiesta de manera coherente y estructurada mediante el lenguaje. Recordemos que Freud ya había destacado la relevancia clave que adquiere el deseo inconsciente y su manifestación mediante los sueños (Freud, 1979), actos fallidos, lapsus involuntarios (Freud, 1979a) y chistes (Freud, 1979b). El análisis más importante y reconocido de todos ellos es, sin dudas, el de los sueños, en el que Freud construirá, a partir del estudio empírico de centenas de casos debidamente

$9 \quad$ Por textos "sociales" se hace referencia a los trabajos que más explícitamente aluden a cuestiones socioculturales y sociopolíticas, o concernientes a la construcción del lazo social, en particular a "El malestar en la cultura", "Psicología de las masas y análisis del yo" y "Tótem y Tabú". En realidad, como se dijo, el propio Freud rechaza la distinción tajante entre la psicología individual y la social, lo que ha llevado a diversos análisis marxistas a recuperar sus contribuciones teóricas (al respecto, véanse, por ejemplo, Marcuse, 1983 y Horkheimer y Adorno, 2002). Este trabajo, no obstante, se centrará en los aportes del psicoanálisis lacaniano, entendiendo que, pese a su indudable herencia freudiana, Lacan presenta profundas críticas a su "maestro", lo que lo aleja en gran medida del freudismo y lo acerca a una especie de post-freudismo que, en algunos casos, es claramente diferente (y hasta antagónico) a los presupuestos freudianos clásicos. Posiblemente, para destacar una analogía plausible dirigida a aquellos lectores de teoría política, Lacan sea a Freud y al freudismo, lo que Laclau es a Gramsci y al marxismo. documentados ${ }^{10}$, toda una simbología particular para expresar su significación cultural. Básicamente, sin centrarse en el detalle específico de este intrincado tema, lo más relevante que descubrió el genio de Freud es que los sueños manifiestan el deseo inconsciente mediante una serie de "condensaciones" y "sustituciones", basadas en la "libre asociación" de símbolos que realiza el sujeto (Freud, 1979).

Lo que hará Lacan (2003), como en tantas otras ocasiones, será retomar esta distinción y complementarla con algunos aportes reformulados de la lingüística estructuralista de De Saussure (1961), en este caso, articulados con las contribuciones de Roman Jacobson (1985) referidas a la metáfora y la metonimia. En ese marco, dirá que la lógica de condensación y sustitución de los sueños, toma la forma de "metáforas" y "metonimias", expresadas mediante la estructura gramatical del lenguaje. A partir de allí, señalará que el inconsciente se manifiesta de manera estructurada y coherente en el sujeto mediante metáforas y metonimias que simbolizan imaginariamente la unidad deseada. Haciendo un paréntesis, se debe mencionar, brevemente, una de las premisas principales del psicoanálisis, que luego se detallará en el punto acerca de la ausencia de relación sexual y sobre el goce. Es la premisa que afirma que todo sujeto, una vez instaurado el orden significante que lo determina (el orden de las

10 Una de las principales (y más curiosas) críticas al psicoanálisis es su presunta ausencia de empiricidad, lo que se vincula, desde el empirismo hegemónico, a la condición de cientificidad y, por lo tanto, de garantía de objetividad de toda teoría. Si bien el psicoanálisis, como afirma Lacan, no es (ni pretende ser) una Ciencia en sentido estricto, representando más bien un método interpretativo, difícilmente pueda hallarse en las Ciencias Sociales y Humanísticas (incluyendo a la Economía), una disciplina tan empírica como aquella. Debemos tener en cuenta, en ese sentido, que para su simbología de los sueños, así como para su análisis de los actos fallidos, lapsus y chistes, Freud recopiló centenas de testimonios, anécdotas y "fallidos" de sus propios pacientes. A partir de la documentación de ese amplio corpus es que elaboró (y luego reelaboró varias veces) su teoría de los sueños, chistes y actos fallidos, como expresiones del deseo inconsciente (véase Freud, 1973a, 1973b y 1979). 
palabras, expresadas bajo la forma estructurada del lenguaje), desea el retorno a la unidad perdida con el cuerpo de la Madre (la llamada Cosa). Como esa unidad es imposible, ya que al nacer se trata de dos cuerpos separados para siempre, a partir de su prohibición (castración fálica), se desea el retorno a la mítica unidad. Precisamente, lo que hace el orden significante es permitir, por la vía de metáforas y metonimias, el retorno imaginario de aquella unidad con la Cosa. En ese marco, para el psicoanálisis adquieren vital importancia las construcciones metafóricas y metonímicas, lo que lleva a indagar en sus indudables implicancias para la teoría política y social, y el análisis sociopolítico.

\subsubsection{IMPLICANCIAS PARA LA TEORÍA Y EL ANÁLISIS SOCIOPOLÍTICO}

Si el inconsciente está estructurado como un lenguaje, $y$ esta estructuración se expresa mediante la utilización de metáforas y metonimias, las cuales sustituyen y condensan la unidad deseada de un modo coherente y posible de ser interpretado, entonces la principal implicancia para la teoría y el análisis sociopolítico, es que el lenguaje adquiere una función crucial. Lacan (2003) retoma, en ese sentido, la distinción entre el significante (la imagen acústica o palabra asociada al concepto) y el significado (el significado o concepto literal) de De Saussure (1961), para señalar la primacía absoluta del primero sobre el segundo (S/s). En ese marco, afirma que el discurso constituye $y$ determina a los sujetos como tales, lo que nos reenvía a su relación directa o indirecta con teorías políticas y sociales como la semiótica social (Pierce, 1955; Benveniste, 1989 y Verón, 1987), la filosofía del lenguaje (Bajtín, 1982 y Voloshinov, 1989), la teoría post marxista del discurso (Laclau y Mouffe, 1987; Laclau, 1996 y 2005), la deconstrucción (Derrida, 1989 y 1997), la epistemología post-empirista (Wittgenstein, 1988) y el pragmatismo anglosajón (Austin, 1998).

Pero además, la primacía del significante conduce a Lacan, como se ha visto, a destacar la relevancia clave que adquieren las metáforas y las metonimias, las que desarrolladas por Roman Jacobson (1985), presentan implicancias cruciales para el estudio de las relaciones entre la retórica y el discurso, con larga tradición en ciencias sociales desde Aristóteles, el Grupo $\mathrm{Mu}$ y los estudios de comunicación (Le Guern, 1976; Lakoff y Johnsonn, 1988), e incluso, recuperadas de forma reciente por el análisis político del discurso (Laclau, 2005 y 2008), entre otras vertientes discursivas.

\section{2. "NO HAY RELACIÓN SEXUAL"}

Siguiendo, en parte, la "herencia" freudiana, Lacan formuló una polémica frase, muy discutida aún, que afirma que "No hay relación sexual". Lejos de entenderla en su sentido literal, la imposibilidad de la relación sexual refiere, básicamente, a la no complementación posible entre el hombre y la mujer. A diferencia de aquellos sujetos que creen (desean) hallar su "media naranja", Lacan les advierte que no existe esa complementariedad, lo que se hace evidente, por ejemplo, en las propias relaciones sexuales concretas, cuando los tiempos orgánicos del hombre y la mujer difieren, además de las inevitables peleas y conflictos de pareja, que no hacen sino mostrar una imposibilidad de armonía y complementación, que Lacan (2006 y 2008) luego extiende, como analogía, al conjunto de la sociedad.

\subsubsection{IMPLICANCIAS PARA LA TEORÍA Y EL ANÁLISIS SOCIOPOLÍTICO}

Las implicancias de esta famosa y controvertida frase para la teoría política y social, $y$ el análisis sociopolítico son muchas $y$ han sido desarrolladas por algunos trabajos ubicables dentro de lo que se conoce como el post-marxismo (Laclau y Mouffe, 1987) y la llamada izquierda lacaniana (Alemán, 2009 y Stavrakakis, 2010). Las mismas se vinculan, en primer lugar, con la traslación de la imposibilidad de la relación sexual del campo individual al social. Siguiendo en parte a Freud (1973c y 1973d) en sus Seminarios 17 y 20 Lacan trasciende el análisis meramente individual, para indagar en algunas implicancias sociopolíticas de su enseñanza. Lo que aquí se debe destacar es que las implicancias de esta frase, para una teoría y un análisis sociopolítico crítico, se 
resumen en la imposibilidad de una sociedad sin la presencia de antagonismos y relaciones desiguales de poder $y$ dominación entre los hombres. En ese marco, resulta harto evidente la vinculación e influencia de esta famosa frase en teorías políticas del discurso recientes, como el post-marxismo post-estructuralista de Laclau y Mouffe (1987), quienes se refieren, desde una orientación lacaniana, a la "imposibilidad de la sociedad" (Stavrakakis, 2008 y 2010), lo que implica la imposibilidad de una sociedad plena y transparente. No obstante, esta crítica a la posibilidad mítica de la unidad total presenta amplios antecedentes que se remontan a la filosofía y la teoría política y social, comenzando por las contribuciones de Nietzsche, siendo moneda corriente en todas las vertientes postestructuralistas y posmodernas, al menos desde las tempranas críticas a la plena presencia de Derrida (1989), al igual que en las visiones de "alcance medio" de la teoría social y cultural contemporánea (Giddens, Beck, Bourdieu, Luhmann, Bauman, etc.).

Otra de las implicancias teóricas y sociopolíticas que pueden extraerse de la controvertida frase lacaniana, aunque desde un marco más cercano a lo ético-político, es la necesidad de no ceder al deseo de retornar a la unidad plena. Como destaca Lacan en su Seminario VII, "La ética del psicoanálisis" (Zizek, 1992), incorporando implícitamente una ética normativa posfundacional, todo sujeto debe aprender a convivir con la falta, ya que el deseo, como la falta, son eternos y constitutivos del "ser parlante". En otras palabras, no solo no existe una sociedad que pueda erradicar la presencia de los antagonismos (Laclau y Mouffe, 1987), sino que además, es necesario aceptar la falta (y Lacan luego agregará que el sujeto no debe ceder al deseo de forcluir aquella falta para cumplir el deseo inconsciente de retornar a la unidad plena), lo que implica, para nuestro análisis sociopolítico, la defensa implícita de un orden social plural y democrático que acepte y respete a la diferencia $y$ al disenso como constitutivos, e incluso como ética y políticamente deseables. De este modo, la teoría psicoanalítica se vincula con las corrientes feministas y queer (antes que las multiculturalistas) y todas sus variantes democrático-liberales y de socialismo democrático, incluyendo los enfoques posmodernos y post-estructuralistas, en favor de la aceptación $y$ promoción de las diferencias políticas y socioculturales, contrario a las lógicas universalistas $y$ totalitaristas de la Modernidad.

\subsubsection{IMPLICANCIAS EPISTEMOLÓGICAS}

Desde el enfoque de Lacan, quien reconoce su influencia por parte de la epistemología crítica de Quine, Feyerabend, Godel, Lakatos, Frege y el "segundo" Wittgenstein (Lacan, 19711972), la imposibilidad de la unidad plena con el objeto se vincula con la imposibilidad ontológica de la objetividad. En efecto, existe una imposibilidad estructural de aprehender la totalidad de la realidad social. Como afirma el pensador francés, la verdad es siempre "no toda", imposible de ser captada en su totalidad por el orden simbólico. No obstante, a diferencia del kantismo y del posmodernismo, que reniega de la posibilidad de acceder a la cosa en sí, Lacan afirma que la verdad puede decirse "a medias" (Lacan, 2008).

Pero además, Lacan nos advierte que los límites de la objetividad no solo provienen de la imposibilidad ontológica del propio decir, sino también del efecto discursivo que construye toda realidad. En efecto, la realidad se expresa, necesariamente, mediante el orden significante. Este, lejos de remitir a una realidad representacional, siempre reenvía a otro significante, esto es, cada palabra remite siempre a otra(s) palabra(s). En ese marco, la famosa y controvertida frase "no hay relación sexual", significa que "no hay un metalenguaje", como destaca en varias oportunidades el propio Lacan (19711972, 2006, 2008 y 2009), es decir, que no existe la objetividad científica, siempre que estamos inmersos en el orden subjetivo y plenamente simbólico del lenguaje ${ }^{11}$.

Un último elemento que impide la objetividad plena -he aquí un aporte fundamental y propio del psicoanálisis- es la presencia inevitable del deseo inconsciente del sujeto. Como destaca Lacan, en tanto somos seres del lenguaje

11 Sobre las críticas epistemológicas de Lacan a la objetividad, véase especialmente Alemán (2010). 
atravesados por el inconsciente, no podemos tener acceso pleno a las cosas en su realidad esencial, es decir, en tanto esencias o fundamentos. En ese marco, no puede establecerse una distinción tajante entre la descripción objetiva y la prescripción normativa, en tanto, como seres parlantes-deseantes, los deseos inconscientes se inmiscuyen necesariamente en todo decir.

En resumen, entonces, se puede decir que la realidad social es, desde el psicoanálisis lacaniano:

1. Construida $y$ determinada por el orden simbólico

2. Atravesada, por lo tanto, por el deseo inconsciente

3. Imposible, a su vez, de ser captada en su totalidad

4. En tanto 1 y 2 , subjetiva ("no hay metalenguaje")

5. En tanto 1 y 3 , relativa ("no toda")

6. En tanto 1, contingente (arbitraria)

7. Por último, en tanto 1 , pasible de ser aprehendida de forma parcial ("mediodicha")

\subsection{LA IDENTIFICACIÓN A TRAVÉS DEL OBJETO PARCIAL}

Frente al orden significante como primordial $y$ determinante en la construcción de la subjetividad, así como en el marco de la imposibilidad de la relación sexual, el psicoanálisis destaca la presencia ineludible de un elemento de identificación, en gran medida inconsciente, que se presenta en todo sujeto bajo la forma de identificaciones en torno a ciertas figuras, símbolos y objetos o ideas. En ese marco, radicalizando los aportes inicialmente señalados, aunque no desarrollados por Freud, Lacan coloca el eje en la posibilidad de que se establezca una identificación subjetiva en torno a ciertos objetos parciales que actúan como sustitutos imaginarios de la Cosa perdida y su imposibilidad de corporeizarse plenamente. Recordemos que Freud, en "Psicología de las masas y análisis del yo", señalaba que en la fase previa al nacimiento existía una unidad plena con el objeto que no requería de identificaciones e introyecciones. No obstante, toda psicología individual es, al mismo tiempo, social, y de allí nace la necesidad de identificación, que en el caso de los textos "sociales" de Freud es, básicamente, mediante la identificación vertical y casi hipnótica, con el líder (ya sea político, religioso o militar), en tanto "ideal del yo" que garantiza seguridad y protección (Freud, 1973d).

En Lacan (1987, 2003), en cambio, se reconoce esta posibilidad identificatoria, pero se subraya la posibilidad alternativa de que la identificación de los sujetos se instituya en torno a un significante "Amo" o significante "primordial" (Lacan, 2006), constituido a su vez, a partir de una "cadena significante" anudada en torno a diversos significantes encadenados, que funcionan como un "objeto parcial", también denominado objeto "petit a", "objeto a" y "objeto causa de deseo" (Dor, 1997). De este modo, además de la posibilidad de identificación directa con el líder, en tanto encarnación directa del Significante Amo (Freud nos brinda el ejemplo paradigmático de la Iglesia y el Ejército, guiados por esta subordinación verticalista), puede producirse el caso de una identificación parcial con el orden significante y desde allí, con su "rasgo unario", convertido en ideal (Lacan, 2006).

\subsubsection{IMPLICANCIAS PARA LA TEORÍA Y EL ANÁLISIS SOCIOPOLÍTICO}

La importancia que adquiere la introducción lacaniana del objeto parcial y su vinculación con el análisis sociopolítico, ha sido señalada desde la teoría política post-marxista por Ernesto Laclau (2005), en algunos de sus últimos trabajos. Allí, a partir de las contribuciones de Copjec (2006), el pensador argentino destaca que el objeto parcial adquiere una vital relevancia para comprender la conformación discursiva de las identidades sociopolíticas, al constituirse mediante una lógica análoga a la del "significante vacío", el cual actúa como "punto nodal" que hegemoniza el espacio social. En efecto, el significante vacío, en tanto equivalente al significante Amo que actúa como el "punto de capiton" que "acolchona" a la "cadena significante" lacaniana (Lacan, 2006) o 
"cadena de equivalencias", según Laclau (Laclau y Mouffe, 1987, Laclau, 1996 y 2005), funciona como un elemento que, pese a ser parcial, es investido de una lógica general o universal, sin perder por ello su inherente particularidad.

En la experiencia sublimatoria, Lacan recalca que el "objeto a" es "elevado", si bien con cierta "pérdida" inevitable (producto de la presencia del lenguaje y la ausencia estructural del verdadero objeto de deseo, lo que impide retornar plenamente a la unidad imaginaria) a la "dignidad" de la "cosa" (Braunstein, 2006). En la teoría postmarxista de Laclau, por su parte, el significante vacío actúa como un símbolo que encarna el orden (imposible) de la comunidad, hegemonizando discursivamente el espacio social ${ }^{12}$ (Laclau, 2005). Luego, cuando se analice el tema del goce, se verá la importancia directa que adquiere esta lógica para el proceso de legitimación política de los liderazgos contemporáneos. Por lo pronto, se debe destacar las contribuciones clave que presenta para el análisis político y en particular, para el análisis discursivo de la política, al subrayar la posibilidad, más aún en el marco sociohistórico y cultural de declinación de la imagen paterna (Berdiel Rodríguez, 2009), de centrarse en el análisis específico de estos significantes primordiales, articulados con sus significados adosados, en la construcción, y posible transformación y desestructuración, de las identidades políticas y las hegemonías ideológicas.

\subsubsection{IMPLICANCIAS EPISTEMOLÓGICAS}

En cuanto a las implicancias epistemológicas, refieren nuevamente a la incorporación de una dimensión estructural subjetiva $y$ deseante, lo que se opone a las perspectivas hiperracionalistas, que entienden a lo social desde una interpretación racional reducida a individuos guiados por una lógica de maximización instrumental de preferencias. En el caso de Lacan, su principal oponente es el conductismo y su lógica técnica e instrumental guiada por la idea de neutralidad valorativa $y$

12 Hemos desarrollado las notables semejanzas entre ambas concepciones en relación a este punto en Fair (2010a) su metodología de intervención "causa-efecto", centrada en la híper-medicalización del paciente. Para la teoría política, se puede pensar como una nueva crítica teórica y epistemológica a los enfoques individualistas e instrumentales de la Teoría de la Elección Racional, que piensan a lo social como la interacción entre individuos egoístas y puramente racionales, guiados por una lógica de maximización de ganancias y minimización de pérdidas.

\subsection{LA TEORÍA DE LOS TRES REGISTROS (RSI)}

Una de las contribuciones más interesantes $y$ fructíferas que nos ha legado la compleja enseñanza de Lacan, en particular desde sus últimos seminarios, es lo que se conoce como la teoría de los tres registros. A diferencia de Freud, Lacan experimentó en la lectura de textos orientados a la topología, la lógica formal aristotélica, la teoría de los conjuntos, así como en las diferentes críticas a la aplicación de estas concepciones en clave positivista, universalista y objetivista, críticas que provienen, en su mayoría, de la lectura de la filosofía analítica y fenomenológica, la semiología pragmatista y la epistemología post-empirista (Lacan, 19711972, 2005, 2006 y 2008). Resulta indudable, en ese marco, su influencia por parte de Pierce y el segundo Wittgenstein (Lacan, 1971-1972), Heidegger (Alemán, 1993 y 2010), Quine, Frege y Lakatos (Lacan, 1971, 1982 y 2008), la dialéctica hegeliana y el materialismo histórico (Lacan, 2006), e incluso la cultura oriental (Lacan, 2009).

Si bien, la caracterización de los tres registros (Real, Simbólico e Imaginario) data de los primeros textos lacanianos (Lacan, 1953), en una primera etapa de su obra, su teoría se orientaba hacia la primacía del orden simbólico. Como se ha señalado, en sus primeros escritos Lacan (1987, 2003) enfatiza en la relevancia crucial que adquiere el orden significante, es decir, el orden de lo simbólico, en la construcción del sujeto y de la subjetividad. En ese sentido, incluirá un segundo componente, denominado imaginario, en el que destacará que toda formación de la subjetividad sólo puede constituirse de modo imaginario, en tanto que el sujeto se encuentra 
siempre "tachado" o "barrado" por efecto del lenguaje, imposible de abarcar y aprehender la totalidad del ser.

No obstante, a partir de una segunda etapa, que se inicia aproximadamente en sus seminarios XVI y XVII, Lacan comenzará a otorgar primacía a un tercer elemento, que denominará lo Real (Zizek, 2003). A diferencia de lo imaginario y lo simbólico, este registro le permitirá colocar el eje en los límites estructurales de toda formación significante, experimentando su imposibilidad de plenitud. Resumidamente, el orden de lo Real, en tanto diferente a la realidad, representa la muestra estructural de que toda realidad simbólica no es más que imaginaria. Recordemos que todo sujeto (y toda realidad social) se constituye mediante el orden simbólico. Sin embargo, ese sujeto y esa realidad son siempre imaginarios, pues se constituyen excluyendo su propia imposibilidad estructural. Lo Real, precisamente, es ese "poco de verdad", posible de ser simbolizado bajo la forma del síntoma histérico, que muestra que la realidad es siempre incompleta y fallida. Es por ello que Lacan (2006 y 2008) nos dice que la realidad es siempre "no toda", pero que, al mismo tiempo, puede ser "medio dicha", lo que habilita en su teoría la presencia de una contingencia ontológica.

Recapitulando, entonces, tenemos en Lacan la presencia de tres registros: el orden de lo simbólico (S), el de lo imaginario (I) y el de lo real (R). Estos tres registros Lacan los escribe RSI y retomando la teoría de los conjuntos, los describe (y escribe) conjuntamente (Lacan, 1971-1972). ¿Qué quiere decir esto?, que estos elementos no están plenamente separados entre sí, sino anudados por un eje central. Lo interesante, sin embargo, es que desde su estructuración, persiste un elemento ocultado o reprimido, que es el del orden de lo Real, es decir, un registro que representa lo imposible, pero que el orden de las construcciones de lo simbólico muchas veces intenta forcluir 0 reprimir en su formación imaginaria de lo que se denomina la realidad. No obstante, su intento (deseo) de forcluirlo, lo Real, en tanto expresión de lo imposible estructural, emerge en algún detalle de la estructura para mostrar los límites inmanentes de la realidad, desestructurándola, de modo tal que si se desata uno de los tres nudos, el total del sistema se modifica $y$ se desintegra.

\subsubsection{IMPLICANCIAS PARA LA TEORÍA Y EL ANÁLISIS SOCIOPOLITTICO}

Las implicancias de esta construcción lacaniana para la teoría y el análisis sociopolítico, pese a que curiosamente han sido desarrolladas con mucho mayor detalle por la filosofía política (Badiou, 2007), resultan evidentes y adquieren una vital importancia. En efecto, entendemos que el denominado nudo borromeo, que anuda los componentes de lo Real, lo Simbólico y lo Imaginario, permite explicar tanto la estructura y organización macro del orden (y del lazo) social, como su capacidad de ruptura, reformulación parcial o desestructuración global. En relación a la estructura del orden social, destacando su componente de construcción imaginaria, vía el orden simbólico. De este modo, Lacan continúa con una lógica similar a la de la semiótica pragmática pierciana y la semiología social en general, así como los aportes de la filosofía analítica, el post-estructuralismo y la deconstrucción derridiana.

No obstante, el elemento sin dudas más interesante es el que se subraya en su última etapa, el de la primacía de lo Real. Mediante la incorporación de este registro y su anudamiento con los otros dos mediante la incorporación de la teoría de los conjuntos, Lacan logra trascender su estructuralismo inicial, brindando importantes herramientas heurísticas a la teoría y al análisis sociopolítico. Por un lado, trasciende las limitaciones de las visiones estructuralistas tradicionales, como las de De Saussure, algunos trabajos de Levi Strauss, los textos iniciales de Pecheux y Althusser o los análisis de Foucault, así como de otras teorías $y$ filosofías cercanas a este enfoque, como el funcionalismo y el estructural-funcionalismo parsoniano y las teorías sistémicas y organicistas, para mostrar los límites inmanentes de toda estructura cerrada. Es así que, como en Derrida (quien, a su vez, se basa en la temporalidad de Nietzsche y Heidegger), se puede decir 
que, en su última etapa, Lacan se constituye en uno de los fundadores del post-estructuralismo, para destacar, a partir del registro de lo Real, las grietas que muestran los límites de toda estructura $y$ por lo tanto, la contingencia $y$ arbitrariedad ontológicas del orden social. En los términos de la teoría política, los límites estructurales de toda construcción discursiva que se pretenda totalizante o universalizante $y$ como derivación de toda utopía de plenitud.

Además, a diferencia de pensadores como Foucault, quien destacaba este elemento de imposibilidad de la plenitud, pero no podía dar cuenta de la capacidad de salida de esa estructura disciplinadora, más allá de oponerle la "resistencia" al "poder" (véase Foucault, 2003), a diferencia también de la Teoría Crítica de Adorno y Horkheimer (2002) y su feroz crítica a la lógica instrumental y "totalizadora" del capitalismo moderno, la teoría de los tres registros, en particular a partir del valor que adquiere lo Real, le permite a Lacan incorporar cierto optimismo de base, en el sentido de que todo sistema siempre muestra, en algún momento, las fallas estructurales. En suma, como afirmara Marx, "Todo lo sólido se desvanece en el aire", permitiendo su transformación. En ese marco, un tercer y último aporte a la teoría y al análisis sociopolítico crítico se encuentra representado por la apertura que genera el componente de lo Real a la emergencia del sujeto político, aquel que solo puede surgir, precisamente, de las fallas estructurales del orden social o en los términos de Badiou (2007), como un efecto sintomático de los "acontecimientos".

Ahora bien, para comprender en toda su magnitud este proceso de desestructuración empírica de la realidad, se debe destacar en Lacan la incorporación de un elemento teórico adicional, clave para construir una política alternativa, como es la presencia del síntoma. Aunque Freud fue el primero en referirse a la relevancia que adquirían los síntomas inconscientes e "histéricos" en los pacientes, Lacan luego enfatizó, desde algunas contribuciones de la lingüística estructuralista, que las "formaciones del inconsciente" adquirían una lógica estructural que se manifestaban mediante una lógica discursiva coherente y pasible de ser interpretada. En ese marco, en su Seminario XVII Lacan (2006) iría más allá de su "maestro", para realizar una serie de analogías vinculadas con la política. En ese sentido, afirmará que Marx "inventó" el síntoma, al tomar al proletario como síntoma de la plusvalía explotadora del capitalismo. Según destacará, este síntoma emergente corresponde a una materialización de la falla en el orden de lo simbólico, lo que permite, paradójicamente, historizar un elemento ahistórico y estructural como es el componente de lo Real. El síntoma, precisamente, permite mostrar empíricamente los límites estructurales de la realidad, abriendo la puerta para su posterior elaboración y transformación subjetiva. En ese contexto, adquiere vital importancia la construcción simbólica que se realiza de aquel síntoma que emerge como lo Real-imposible, ya que de su elaboración dependen sus efectos. En el caso del análisis político, las construcciones socioculturales que se efectúen de determinado síntoma social, junto a las construcciones discursivas de sus condiciones de posibilidad, permitirán que el "acontecimiento", en tanto efecto de lo Real, pueda expresar o no la emergencia del sujeto político y en el mismo sentido, la orientación político-ideológica que tendrá aquel sujeto emergente, que podrá irrumpir como un sujeto popular crítico y democratizador del orden vigente o bien, como un sujeto restaurador de la estructurada barrada, en un sentido reaccionario.

A modo de resumen ordenador, se puede sintetizar los aportes de la teoría de los tres registros lacanianos, a la teoría y al análisis sociopolítico crítico, en los siguientes términos:

1) A partir del nudo borromeo, permite explicar tanto la estructura y organización macro del orden ( $y$ del lazo) social, como sus límites y su capacidad de ruptura, reformulación parcial o desestructuración global, destacando su componente de construcción imaginaria mediante el orden simbólico y la latencia desestructuradora, en tanto efecto de lo Real.

2) Como derivación del punto anterior, la teoría de los tres registros explica que 
la construcción del orden social se establece por la vía del orden simbólico y se estructura de forma imaginaria.

3) Además, en particular mediante el registro de lo Real como imposible estructural, muestra los límites inherentes y la imposibilidad estructural concreta de toda construcción hegemónica y de toda utopía de plenitud, universalidad o totalización.

4) La ahistoricidad de lo Real permite incorporar, junto a las determinaciones estructurales, cierto optimismo de base, en el sentido de que todo sistema siempre muestra, en algún momento temporal, las fallas estructurales que expresan su imposibilidad.

5) La emergencia de lo Real-imposible presenta la posibilidad de ser metabolizado en el orden simbólico, bajo la forma de síntomas.

6) La metabolización simbólica de los síntomas, en términos sociopolíticos, abre la posibilidad para la emergencia del sujeto político y su capacidad potencial de transformar radicalmente el orden vigente (aunque también habilita la posibilidad de que el sistema retorne a un discurso similar al existente, e incluso más reaccionario y explotador).

Pensando esta lógica en los términos de la teoría política del discurso de Laclau (1993, 1996 y 2005), se puede decir que no existe una sociedad sin antagonismos, la sociedad (plena) es "imposible" y se encuentra estructuralmente "dislocada", por lo que la formación del orden comunitario no puede ser más que hegemónica ("no toda"). La llamada "lógica de la diferencia", en ese sentido, habita reprimida para emerger estructuralmente. Precisamente, la metabolización discursiva que se deriva de los efectos sintomáticos de la emergencia del componente de lo Real-imposible, es lo que permite comprobar, en el plano simbólico, la premisa de que toda realidad social está siempre fallada 0 barrada, esto es, que hay un hueco reprimido que, "más allá del análisis del discurso" (Zizek, 1993), pulsa por aparecer y en algún detalle de la estructura, siempre aparece para mostrar esos límites inmanentes.

Se señala, por lo tanto, que el síntoma social, en tanto simbolización de ese "poco de realidad", permite la mostración fáctica de la "dislocación" (Laclau, 1993) o la "heterogeneidad radical" (Laclau, 2005) de toda formación social hegemónica, "reactivando" lo social "sedimentado" (Laclau, 1993) ${ }^{13}$. Continuando con las contribuciones implícitas que brinda este autor, se puede afirmar también que, desde el análisis psico-socio-político del discurso, un síntoma político se constituye cuando esta emergencia de lo imposible logra metabolizarse simbólicamente (un proceso que siempre es retroactivo) para constituir un nuevo lazo social alternativo y consistente que resulta antagónico del orden hegemónico y al mismo tiempo, se presenta desde una lógica de la universalidad "barrada". Un ejemplo de ello, que hemos trabajado en otro lugar (Fair, 2009b), es la irrupción de los trabajadores desocupados conocidos como los piqueteros, surgidos durante el año 1996 en Argentina, al calor del discurso hegemónico neoliberal del menemismo y los despidos de empleados públicos promovidos por el proceso de privatizaciones. Este discurso alternativo logró constituirse, bajo ciertas circunstancias que remiten a su lógica de articulación política, como un síntoma "espectral", en el sentido derridiano (Derrida, 1995), mostrando los límites ontológicos del discurso universalizante y totalizante del menemismo, si bien, se podría decir que algo frágil para expresar de forma duradera y consistente el antagonismo.

Biglieri (2006), de un modo similar, se ha referido a la emergencia de un discurso ( $y$ una práctica discursiva) horizontal y asamblearia, emergente en la Argentina del 2002, como un síntoma sociopolítico de la profunda crisis del orden liberal-democrático que crujió con la crisis $y$ derrumbe del neoliberalismo, hacia fines

13 Cabe destacar, en la obra de Laclau, la presencia de algunas contradicciones conceptuales en relación a la categoría de lo Real, que en algunas ocasiones es vinculada a la noción de "antagonismo" (Laclau y Mouffe, 1987), mientras que en otras, más recientes, el autor logra dilucidar su componente más estructural de "dislocación" (Laclau, 1993) o "heterogeneidad radical" (Laclau, 2005). 
del año anterior. El propio fenómeno político del kirchnerismo puede ser visto también, al igual que el chavismo, entre otros gobiernos críticos de la ortodoxia neoliberal, como síntomas políticos de la hegemonía de la globalización neoliberal, al establecer un proceso de "inclusión radicalizada" (Barros, 2006), antagónico de muchos de los principios centrales del neoliberalismo excluyente, aunque, como siempre, esta caracterización responde a una cuestión de interpretación política (subjetiva) del analista $^{14}$. El problema principal, en todo caso, es que como se ha señalado anteriormente, este síntoma político o sociopolítico que emerge de la ruptura del nudo borromeo que estructuraba determinado orden social, no siempre es "progresista" o "rupturista".

En ese sentido, se tiene el ejemplo del nazismo en la Alemania posterior a la crisis de la República de Weimar y a la propia Europa de hoy, cuyo sistema socioeconómico de "valorización financiera" del capital (Basualdo, 2000) ha ingresado en una profunda "crisis orgánica" (Gramsci, 1984), aunque ello ha conducido en la mayoría de los casos, a la emergencia de un discurso dominante restaurador o conservador del viejo orden neoliberal, si bien, mezclado con otros discursos "progresistas", fuertemente críticos del modelo de acumulación y otros tantos xenófobos y conservadores de derecha, en el plano social. Lo más relevante de este proceso es que nada en la estructura misma del sistema indica que la política emergente de lo Real sea necesariamente "progresista" o "demócrataradical", pudiendo irrumpir, en los términos de Laclau (2005), discursos institucionalistas o tecnocrático-gerenciales, discursos "populistas" de izquierda, "populistas" de derecha o bien, una mezcla compleja de ambos, entre otras opciones posibles.

Este elemento se vincula con una segunda "función" que presenta el componente de lo Real en términos sociopolíticos. Por un lado, si expresa la emergencia de la falla y su posibilidad (siempre potencial) de ser simbolizada mediante síntomas sociales/políticos, también abre el paso a lo incalculable. En efecto, si es cierto que

14 Acerca de la teoría de los cuatro discursos en Lacan, véase Álvarez (2006). lo Real se observa siempre en sus efectos, los efectos de lo Real no pueden ser nunca controlados o gestionados en su totalidad. Es por eso que Badiou afirma que la política del psicoanálisis consiste en hacer lo "imposible" (Badiou, 2007), lo que permite, precisamente, la emergencia de un sujeto político que realice una transformación de incalculables e imprevistas derivaciones, mientras que Laclau incorpora al mismo tiempo, la necesidad de promover una disputa hegemónica por defender una política a favor de la "emancipación" popular ("no toda") y la profundización de una democracia "radicalizada" y "plural" (Laclau y Mouffe, 1987; Laclau, 1996).

\subsubsection{IMPLICANCIAS EPISTEMOLÓGICAS}

Las implicancias epistemológicas de la teoría de los tres registros se vinculan con una profundización de las contribuciones de la epistemología crítica y la filosofía analítica, en torno a la imposibilidad de aprehender la realidad social en su totalidad. Lacan se constituye, así, en un fuerte crítico de la idea de objetividad $y$ neutralidad valorativa, aunque incorporando, como una nueva crítica, el componente de deseo inconsciente que sobredetermina al propio lenguaje $y$ al propio sujeto, elementos subjetivos que son imposibles de ser desligados, en tanto habitan en el propio lenguaje que estructura la realidad. En cuanto al componente específico de lo Real, como se destaca, incorpora un elemento interesante en términos epistemológicos, ya que permite complejizar el clásico debate objetividad-subjetividad, sin caer en un relativismo posmoderno de construccionismo radical. Lo Real, precisamente, no es ni plenamente interno al sistema, ni plenamente externo. Se trata de un componente "éxtimo" que, como el punto cero, es al mismo tiempo interno y externo. En todo caso, lo Real es como un equivalente al elemento olvidado por el orden simbólico, el número 0 de la cadena numérica que, como el inconsciente, siempre retorna para mostrar su existencia, una existencia que se expresa en la imposibilidad del Uno todo. Pero además de este olvido del 0 , se ha visto que el componente de lo Real también abre el paso a lo incalculable o inimaginable. 
Lacan (1971-1972) se refiere, en ese sentido, a la construcción de la cadena 1, 2, 3, 4. La lógica indica que el paso siguiente sería $5,6,7,8$. No obstante, uno bien puede escribir 9, 10, 11, 12 y luego 17, 18, 19, 20. O bien, puede modificar en su totalidad la propia lógica que presenta la estructura de la cadena, escribiendo 1, 2, 3, 4 y luego 5, 7, 9, 11, lo que habilita opciones infinitesimales. Pues bien, la misma lógica de lo imposible e incalculable es la que domina a una política transformadora, una política que es capaz de realizar lo visto, impuesto o pensado como imposible, hasta entonces, por el orden dominante.

\subsection{LA TEORÍA DE LOS CUATRO DISCURSOS}

Uno de los aportes sin dudas más relevantes y estimulantes que ha brindado la teoría psicoanalítica lacaniana, es la llamada teoría de los cuatro discursos. Esta teoría, aunque presente también en su texto "Radiofonía y televisión", la desarrolla el pensador francés en su Seminario XVII, en plena ebullición política estudiantil de Mayo del 68. Para ello, Lacan tomará como referencia un curso realizado con el filósofo ruso Alexander Kojeve, que le permitirá recuperar algunas referencias hegelianas en clave crítica. Además, Lacan aplicará también algunas contribuciones provenientes del marxismo, que luego indicaran cuando se vea el tema del goce.

Finalmente, desarrollará un análisis discursivo que tomará como eje una topología matemática basada en matemas o letras, que simbolizan (y sintetizan) las posiciones de cada uno de los discursos (se trata de posiciones discursivas de sujeto, un concepto que se asemeja en gran medida a la noción de "posiciones de sujeto" de Foucault). Resumidamente, Lacan (2006) destaca la presencia de cuatro macrodiscursos que estructuran el lazo social: el discurso del Amo, el discurso Universitario, el discurso del Analista y el de la Histérica. Luego, incorpora un quinto discurso, que define como el discurso Capitalista. Cada uno de estos discursos, expresado en un conjunto de matemas que van variando sus posiciones, constituye una modalidad diferente de construir $y$ estructurar el lazo social y contiene su propia especificidad en lo que refiere, en términos de la teoría política, a su modalidad de legitimación sociallit

En primer lugar, el denominado discurso del Amo antiguo, toma como referencia al Amo de la Antigüedad que analiza Hegel, para destacar la dialéctica que se establece en la relación Amo-Esclavo. En ese marco, Lacan afirma que el Amo domina políticamente mediante su poder de coacción y el Esclavo obedece por obligación y miedo.

El discurso del Universitario o discurso del Amo moderno, nos ubica, en cambio, en la Modernidad. La dominación ya no proviene de la fuerza física y el temor, sino más bien del saber superior. Como lo analizara Foucault (2003) y lo desarrollaran críticamente los enfoques posmodernos (Lyotard, 1992), el poder se vincula directamente al saber como un modo de dominación. En el caso de Lacan, su crítica se dirige a la corriente conductista, así como, a la psicología científica y a las neurociencias, que a partir del presunto saber superior de la psiquiatría y la medicina anglosajona, prescribe "científicamente" medicamentos que prometen la curación del paciente casi por arte de magia. Lacan, en cambio, sostendrá que la curación proviene de las interpretaciones del analista $y$ por lo tanto, de los efectos performativos de curación que bajo ciertas condiciones, adquiere la palabra, lo que explica su oposición al cientificismo de la psiquiatría y la medicina tradicional, aunque también su posición de analista no plenamente antagónica al discurso de la Ciencia.

15 La interpretación de los liderazgos "progresistas" de la región como antagónicos del neoliberalismo puede resultar un poco extrema y es motivo de importantes debates entre los analistas políticos. En cuanto al tema de los grados de radicalidad de estos liderazgos emergentes, es motivo también de debate si es posible referirse, desde la teoría del populismo de Laclau, a una inclusión social del sujeto "pueblo" que presente o no diversas gradaciones (para un enfoque a favor, véase Aboy Carlés, 2005. Para un enfoque opuesto, véase Barros, 2006). Desde la "izquierda lacaniana", el eje, en todo caso, radica en la pregunta de si se puede pensar en "acontecimientos" sintomáticos que expresen diversos grados de ruptura con el orden simbólico, en una especie de desestructuración "parcial" (y no siempre total) del orden hegemónico. 
El discurso de la histérica se caracteriza por ser un discurso "no todo", esto es, un discurso que se mantiene (y goza) del deseo expectante del otro, de la negación permanente. En ese marco, se sitúa, con independencia del género, en una posición femenina crítica de los universalismos que históricamente ha detentado la posición masculina y patriarcal del Amo. Como lo ha trabajado Alemán (2010), este discurso muestra las inconsistencias del discurso Amo, quien se presenta como un todo universal $y$ objetivo, olvidando las fallas constitutivas (expresadas en frases contrarias a la lógica universal aristotélica, como "hay al menos uno que", "no todo", "la mujer no existe", etc.).

Finalmente, el cuarto discurso, aquel en el que se posiciona el propio discurso de Lacan, es el del Analista. Al igual que el de la Histérica, este discurso se mantiene en la lógica del no todo, esto es, en la imposibilidad de la relación sexual, lo que implica el rechazo teórico a la posibilidad de una unidad plena del sujeto, extendido a la pareja y al resto de la sociedad, $y$ al mismo tiempo, el rechazo epistemológico a la idea de objetividad del Discurso Universitario, ya que este discurso, al igual que el del Capitalismo, no acepta las fallas ontológicas que impone el inconsciente estructurado como un lenguaje. Un inconsciente que, ya sea mediante actos fallidos, lapsus, chistes, síntomas histéricos (por ejemplo, dolores psicosomáticos sin una base orgánica), de todas maneras siempre emerge en lo Real, para mostrar los límites y la imposibilidad de la realidad social, tal como fue estructurada.

Ahora bien, a diferencia del discurso de la Histérica, centrado en la pura negatividad de lo universal, el discurso del Analista promueve una positividad centrada en la formación de un nuevo lazo social para el sujeto, lazo que se constituye, precisamente, a partir de una determinada cadena de significantes que se anudan en un significante Amo y sobredeterminan las amarras de cada sujeto. Tampoco debe ser confundido este discurso con el científico o Universitario, ya que, si bien es cierto que se legitima en el saber superior del analista, esta presunta superioridad es solo "estratégica", tendiente a generar una "transferencia" (conexión libidinal) que permita tener eficacia performativa en el paciente, solucionando sus síntomas y fantasías, así como, reconduciendo su goce inconsciente por otros caminos. Como se dijo anteriormente, el discurso, al igual que el sujeto, está siempre y desde el inicio, barrado o tachado (\$), por lo que el saber superior no puede ser más que mítico (de allí que Lacan se refiera al sujeto "supuesto saber") ${ }^{16}$.

Finalmente, el discurso del Capitalismo o discurso capitalista constituye un quinto discurso formador del lazo social, que Lacan incorpora a los cuatro anteriores. Se caracteriza, básicamente, por incentivar el deseo infinito de consumo masivo de mercancías causadas para crear su deseo y como lo analizara Marx, en la necesidad creada de la máxima acumulación posible de ganancias económicas, en tanto orden significante construido como sinónimo de una mayor felicidad individual que "tapona" o "llena" imaginariamente la "falta". Lacan destaca que el discurso del Capitalismo y el discurso del Universitario se encuentran hoy al servicio de la dominación del Amo moderno, lo que tiene, nuevamente, enormes implicancias, las cuales se analizarán.

\subsubsection{IMPLICANCIAS PARA LA TEORÍA Y EL ANÁLISIS SOCIOPOLÍTICO}

Las implicancias de la teoría de los cuatro discursos para la teoría y el análisis sociopolítico son inestimables. Pese a que no existen muchos trabajos empíricos o aplicados sobre el particular, se entiende que estas contribuciones presentan una estructuración que claramente

16 Lacan, en tanto posicionado dentro del campo del psicoanálisis, necesitaba legitimar su posición para obtener eficacia en su propio análisis, por lo que no podía ubicarse en una posición puramente simétrica a la de sus analizantes. Si bien descreía (y criticaba) el saber superior, la transferencia libidinal solo podía ser posible performativamente mediante la creencia en el saber superior del analista. Tal vez por ello es que su escritura apeló, además, al uso de las matemáticas. Es posible que esta confusión entre el discurso del analista de Lacan y el discurso de la Ciencia o del Universitario, fuera una de las causas de las interpretaciones erróneas de su teoría y de las críticas recibidas, debido a su supuesto retorno a un discurso cientificista y objetivizante. 
puede ser descripta como una teoría social o una teoría política contemporánea ${ }^{17}$. En ese marco, los aportes que se derivan de estos cuatro discursos pueden ser utilizados para realizar una genealogía de las diversas formas de dominación política o bien, para dar cuenta de las estrategias de dominación del Amo moderno en la actualidad. En ese marco, su utilización permite desarrollar una crítica al funcionamiento actual del sistema capitalista $y$ a sus diversas y cambiantes modalidades de estructuración $y$ legitimación social. Para citar solo una posibilidad, se puede destacar que, en la actualidad, la dominación del capitalismo se basa, como ha sido trabajado por diversos autores de la teoría y filosofía política contemporánea y la sociología cultural, en la conjunción de un discurso Capitalista centrado en una lógica de consumo masivo que crea necesidades para el sujeto mediante la televisión y sus propagandas desreguladas, así como, la acumulación incesante de riquezas que promueve el sistema como modo presunto de adquirir felicidad y libertad individual ${ }^{18}$, así como la más reciente legitimación del neoliberalismo mediante un nuevo discurso Universitario centrado en la presunta superioridad de la ciencia económica por parte de los tecnócratas neoclásicos y la idea mítica de objetividad científica con la que se presentan ellos mismos, los periodistas y comunicadores sociales, los mismos que funcionan como "intelectuales orgánicos" que suturan la hegemonía neoliberal globalizadora ${ }^{19}$.

Por otra parte, si se aplica las categorías lacanianas al análisis sociopolítico crítico, se

17 Si tenemos en cuenta que toda sociología política se vincula con la conformación del lazo social y la teoría de los cuatro discursos de Lacan refiere, precisamente, a cuatro posiciones que constituyen, desde el orden simbólico, el orden social, entonces se puede inferir que al menos este seminario, se emparenta en mucho con una teoría y una sociología política de lo social, por la vía del discurso.

18 Esta crítica al hipermercantilismo y a la lógica capitalista de las industrias culturales, en una coincidencia con el pensamiento lacaniano, encuentra antecedentes que pueden hallarse en la Teoría Crítica de la Escuela de Frankfurt (véanse Marcuse, 1983; Adorno y Horkheimer, 2002). puede criticar también al discurso "histérico" de los enfoques posmodernos o de construccionismo radical, así como a algunas corrientes post-estructuralistas y pragmáticas, las cuales solo se basan en la lógica política del no-todo, olvidando la necesidad de constituir una positividad que edifique un nuevo lazo social alternativo (si bien, siempre barrado). Esta misma crítica es también la que puede hacerse desde un pensamiento post-marxista, a perspectivas lacanianas que, como la que presenta Zizek (1992, 2003), pretenden atravesar la fantasía o fantasma imaginario en el que se estructura toda realidad social, aunque sin articular un lazo social (barrado) antagónico ${ }^{20}$. La propuesta de pensar en un lazo social "parcial", tal como lo presenta implícitamente Lacan, permite reforzar, por otra parte, las similitudes existentes entre el enfoque lacaniano y la teoría política del discurso de Laclau (1996 y 2005), quien trasciende también la mera "diferencia ontológica" (Marchart, 2009) de los enfoques post-heideggerianos de izquierda, las filosofías estructuralistas, las posmodernas y las nietzscheanas de construccionismo radical, para recuperar la necesidad de edificar nuevas construcciones hegemónicas alternativas, sin olvidar por ello la defensa de la pluralidad y el disenso como constitutivos ${ }^{21}$.

20 Esta crítica teórica y política es la que le realiza recientemente Stavrakakis (2010) a Zizek, al entender que el filósofo esloveno defiende un modelo "histérico" sobre la teoría de Lacan, cuando en realidad esta visión solo es defendida por este autor en una primera etapa, cuando toma como analogía de la acción al mito griego de Antígona. En una segunda etapa, en cambio, Lacan promueve la formación de un nuevo lazo social (parcial) que trasciende la simple negación del orden instituido (una negación del sistema capitalista que parece ser la única construcción política que presenta en sus textos Zizek). Para una crítica a la (ausencia de una) teoría política de Zizek, que comparte los principales presupuestos de Stavrakakis, véase Laclau (2003, 2005 y 2008).

21 En una especie de "punto intermedio", se puede hallar al análisis filosófico político de Badiou, quien retoma a Lacan y a sus aportes provenientes de la teoría de los conjuntos, para destacar la necesidad de metabolizar y elaborar los "acontecimientos" que, como los síntomas lacanianos, permitan constituir nuevas formas alternativas de emergencia 


\subsection{LA IMPORTANCIA DEL GOCE Y DEL PLUS DE GOCE}

Como señala Braunstein (2006), una de las categorías clave que creara la teoría lacaniana (2006, 2008 y 2009), ausente en la obra de Freud, es la de goce. A diferencia de lo que corrientemente se cree, el goce no implica necesariamente una equivalencia directa con el placer. Incluso, en muchos casos, el goce es no placentero y hasta doloroso. Retomando algunas cuestiones analizadas por Freud en "Más allá del principio del placer", a partir del ejemplo de Sade, Lacan (1987b) recupera, en su última etapa, la importancia crucial que adquiere el goce. A su vez, el célebre pensador francés se basa en la noción de plusvalía de Marx, para referirse también a la relevancia que adquiere lo que llama el "plus de goce" (Lacan, 2006 y 2008). Básicamente, lo que señala Lacan es que el discurso está investido libidinalmente de un goce inconsciente, si bien el goce no pertenece a priori al orden del lenguaje, siendo independiente de aquel (Braunstein, $2006 y$ Stavrakakis, 2010). El goce mayor es, originariamente, el que se deriva de la unidad plena y corporal con la Cosa perdida (la Madre). Sin embargo, se ha visto que ese goce sexual cuerpo a cuerpo es estructuralmente imposible. En ese marco, a partir de la castración instaurada por el significante, se busca su retorno mediante formaciones discursivas que se invisten de goce, si bien siempre presentan una pérdida inevitable de goce, ya que son goces lenguajeros (Braunstein, 2006), esto es, goces del lenguaje (Lacan, 2008).

Se debe recordar, en ese sentido, que una de las premisas fundamentales del psicoanálisis

del sujeto político y de producción "no toda" del lazo social. No obstante, si bien se presenta aquí una recuperación del sujeto $y$ de su libre capacidad de acción política, Laclau le critica a este autor que no explique cómo realizar operativamente la articulación política, además de olvidar la necesidad de pensar esa articulación desde el Estado, en una crítica a su cosmovisión política maoísta $y$ autonomista, desde el post-gramscianismo. Una crítica política similar realiza Laclau a los proyectos anarquistas $y$ autonomistas que promueven los enfoques de Ranciere, de Hardt y Negri (véase Laclau, 2008). lacaniano es el deseo de unidad corporal con ese objeto de deseo primordial, imposibilitado por la castración fálica instaurada por el orden simbólico. A partir de entonces, imposibilitado de regresar al paraíso imaginario de plenitud y transparencia, se desea su retorno, expresado mediante las construcciones inconscientes del lenguaje, los "fantasmas", que a su vez, están investidos de goce. Como se señaló, para Lacan (2006 y 2008), el goce principal es el goce de la unidad o goce "unario", que rememora imaginariamente el goce original de unidad corporal con la madre y luego con su pecho, constituido en el primer objeto a un objeto causa de deseo (Dor, 1997). En ese marco, intentando recuperar el goce perdido, se construyen diversas edificaciones teóricas, a partir de metáforas y metonimias, las cuales intentan suplir la imposibilidad del retorno a la unidad corporal, sustituciones $y$ condensaciones inconscientes del Uno-todo que se expresan siempre por la vía del lenguaje, pero que están investidas libidinalmente (sexualmente) del goce unario. Del mismo modo, se tienen relaciones sexuales de pareja que representan un goce para los órganos sexuales masculino y femenino, respectivamente, y se desea o se consume droga o psicofármacos para acceder al goce perdido (Sissa, 1968). En todos los casos, se busca por todos los medios la materialidad del goce, destacándose el rechazo a la "liviandad" del discurso y la necesidad de materializaciones concretas que otorguen corporalidad a las experiencias, tal como resulta típicamente en el consumo de mercancías de diversa índole, ofrecidos como objetos "causa de deseo" que intentan llenar imaginariamente el hueco o la falta constitutiva que origina la presencia del orden significante, por la vía, precisamente, del lenguaje (Lacan, 2006 y 2008).

Además, retomando a Marx y su invención del síntoma, a partir de la noción de plusvalía, Lacan (2006) inventa el término "plus de goce", para dar cuenta de un plus o un "más allá del lenguaje", que incorpora un suplemento inconsciente de goce para el sujeto. Siguiendo, en parte, a Freud, afirma que la mirada y la voz son fuentes de goce inconscientes para el sujeto. Ello nos remonta a las primeras fuentes de 
goce, asociadas a la mirada de la madre sobre el niño y a la voz de la propia madre, luego vinculadas a las órdenes y pedidos que el niño obedece para ser premiado simbólicamente (por ejemplo, con una sonrisa, un abrazo o un simple agradecimiento y alegría) por la madre. La madre, junto con el padre, se constituyen así, en las figuras que representan el superyó del sujeto, es decir, la conciencia moral que les dice lo que deben o no hacer y desear. Con el proceso de socialización secundaria, este plus de goce se vincula al cumplimiento de órdenes, sacrificios, deberes, imposiciones que se presentan bajo la forma de leyes y mandatos obligatorios por parte de nuevos sujetos considerados importantes para cada uno, ya sea por admiración o temor (Berger y Luckmann, 1997). En ese marco, volviendo a Lacan, el (plus de) goce se vincula al cumplimiento de esos mandatos, deberes, deseos y valores socioculturales constituidos como imperativos (iigoza!!), como puede ser el mandato superyoico de ser reconocido socialmente, ser escuchado, ser visto, etc., pero también las imposiciones políticas y socioculturales típicas del capitalismo neoliberal, como ir de compras (shopping), acumular mucho dinero u operarse mediante cirugías estéticas innecesarias, en tanto constituidos como equivalentes imaginarios de significantes de "valor" para el sistema, vinculados a elementos como ser exitoso, acceder a la felicidad y seguridad individual.

\subsubsection{IMPLICANCIAS PARA LA TEORÍA Y EL ANÁLISIS SOCIOPOLÍTICO}

Las implicancias de la construcción del concepto de goce y plus de goce para la política han sido destacadas por el propio Lacan (2006 y 2008), quien recuerda que, históricamente, los regímenes políticos apelaron a diferentes metáforas de la corporalidad, como modos de acceder imaginariamente al goce unario. En ese marco, se debe recordar que en el transcurso de la historia, han proliferado múltiples metáforas organicistas de la unidad $y$ hermandad que han variado en su significación contextual, sin desaparecer nunca. A su vez, han existido diversas filosofías del ser en plenitud, como el platonismo, el empirismo, el contractualismo, las teorías sistémicas y funcionalistas, el conductismo, el positivismo lógico, las teorías consensualistas, $y$ experiencias "realmente existentes", como la religión judeo-cristiana y los fascismos $y$ totalitarismos de izquierda $y$ derecha, que han intentado, ya sea reconociendo o no el conflicto como base, una síntesis final unaria en el que desapareciera el sujeto y, con él, la acción política, el conflicto, el poder y los antagonismos. Desde el análisis lacaniano, se puede decir que todas estas construcciones imaginarias están investidas inconscientemente del goce unario, lo que explica su persistencia, su (relativa) eficacia y su perdurabilidad temporal adaptada (Fair, 2010b) $^{22}$.

Del mismo modo, el concepto lacaniano de plus de goce puede ser aplicado para comprender el goce suplementario que se asocia históricamente a todo discurso hegemónico. El propio Lacan (2006) destaca, en su teoría de los cuatro discursos, que las cinco posiciones discursivas se encuentran adosadas a un componente de goce inconsciente que funciona como factor de adhesión o en los términos de la sociología política, de legitimación política. Así, si en la Antigüedad el plus de goce se vinculaba al hacer del esclavo, quien sentía que su existencia tenía sentido, ya que era al menos reconocido (identificado) y era considerado "importante" para el Amo antiguo, el Discurso Universitario coloca al goce del lado del Amo, quien tiene el "saber" sobre lo que se debe hacer. Por su parte, en el Capitalismo, el goce se encuentra en el cumplimiento de los diversos mandatos superyoicos del consumo de gadgets, significantes asociados a la felicidad del sujeto $y$ al "taponamiento" imaginario de la falta, lo que reenvía nuevamente a la autonomía imaginaria del sujeto.

Radicalizando estas contribuciones para el análisis político crítico, se puede observar su capacidad heurística para explicar al menos parte de la lógica de dominio sociocultural (político) del capitalismo e incluso, de su fase de globalización neoliberal. En efecto, si el capitalismo basa su lógica de dominación general en el consumo masivo de mercancías creadas

22 Sobre el particular, véase especialmente Stavrakakis (2010). 
para causar su deseo y en la acumulación de ganancias empresariales a partir del plus de valor del trabajo asalariado, algo no muy distinto de lo que había advertido Marx (2000) hace más de un siglo y medio, Lacan nos va a decir que prestemos atención también al plus de goce adherido al discurso hegemónico. Así, se puede afirmar que los mandatos $y$ deberes promovidos $y$ prescriptos como obligaciones superyoicas por las empresas concentradas y los representantes empresariales escenificados en los medios masivos de comunicación, en particular la televisión y su lógica desregulada a favor del consumo y la acumulación de ganancias privadas sin límites, no solo permiten reproducir la explotación capitalista, sino que pueden ser vistos como un modo mítico de alcanzar la libertad y la felicidad individuales, constituyéndose en un plus de goce para el sujeto que permite la adhesión conservadora al sistema y en ese marco, el apoyo a las políticas "liberalizadoras".

En el contexto mundial de declinación del padre restrictivo de antaño, aquel vinculado por el discurso (neo)liberal al Estado Benefactor Keynesiano y sus políticas "autoritarias" de control sobre la economía y limitación de las libertades, derechos y garantías individuales, surge entonces, un mundo sin limitaciones para el libre goce del sujeto (Lebrun, 2003) esto es, un mundo "moderno" y "evolucionado", en el que el sujeto parece recuperar su autonomía y libertad, frente al dominio del Amo antiguo y regulador del Estado burocrático $y$ autoritario (o incluso, dictatorial) de antaño. Al mismo tiempo, este plus de goce, ubicado del lado del "Esclavo", se ve fortificado por una tendencia opuesta, basada en la expansión del Discurso Universitario. A diferencia del discurso del supuesto saber que analizaba Lacan, crítico de la filosofía teleológica de la historia que condujo al marxismo "realmente existente" a la burocratización y a la barbarie estalinista, que llevó a Europa a adherir al nazismo y el fascismo, el neoliberalismo globalizado presenta un segundo elemento que funciona como plus de goce, expresado en el saber superior con el que se legitiman los tecnócratas y gerenciadores de la política, posicionados discursivamente como ajenos a lo "emocional", "arbitrario", "irracional" e "interesado" o "ideológico", valores negativos asociados a la "clase política" y contrapuestos a un (presunto) saber "técnico", "objetivo", "racional", "atemperado", "sensato" y "superior", condición de posibilidad para solidificar aún más el discurso de la globalización neoliberal.

De este modo, se puede decir que el discurso del capitalismo neoliberal presenta una lógica de dominación sistémica centrada en al menos cuatro elementos clave:

1) El triunfo hegemónico de los valores socioculturales impuestos por el capitalismo financiero desregulado, en el marco de la caída de la imagen paterna, frente al control "autoritario" sobre la iniciativa $y$ la libertad privada e individual, vinculado al modo de funcionamiento y regulación del Estado Social de posguerra.

2) El goce derivado del uso de nuevas metáforas unarias, como la idea de "aldea global" o el "Fin de la Historia" y de los "grandes relatos", que refuerzan la hegemonía discursiva y sociocultural del modelo de globalización neoliberal, ya que se impone la percepción de que las confrontaciones $y$ antagonismos quedaron "superados" por la "historia" y no existe un Amo con quien antagonizar y construir la propia identidad política ${ }^{23}$.

3) El plus de goce derivado de un discurso liberal-democrático a favor de la presunta autonomía y felicidad individual, el cual permite que el sujeto pueda consumir, acumular $y$ vivir libre $y$ democráticamente, sin las "interferencias" "arbitrarias" y "autoritarias" del Estado, por

23 En la actualidad, con el retorno de la "alteridad" bajo la forma de nuevos liderazgos políticos y movimientos sociales más críticos y organizados contra el "Pensamiento único" neoliberal, habría que pensar en una posible reversión de este discurso hegemónico y en la misma medida, en un cambio de registro de sus metáforas unarias habituales, aunque la función de "taponamiento" de la falta permanece presente, ya que el propio dinero y la lógica de consumo mercantil del capitalismo, cumplen esa función imaginaria. 
lo que, a diferencia del modelo benefactor keynesiano-regulador, el goce ilimitado y la autonomía nuevamente quedarían posicionados del lado del "Esclavo".

4) La presencia de un elemento adicional, signado por el endeudamiento del sector privado en el plano financiero, que actúa como una tercera pata que consolida la hegemonía del discurso neoliberal, al permitir no solo la reproducción económica de las dos variables clave del sistema capitalista actual (acumulación económica y consumo masivo), sino también la existencia de crecientes demandas sociales conservadoras en torno a la permanencia del sistema neoliberal, en el marco del temor generalizado a que una devaluación monetaria destruya económicamente a los sectores endeudados e impida continuar con las pautas socioculturales imperativas.

5) Por último, la solidificación del discurso hegemónico, a partir de la función unaria de tecnócratas neoliberales de presunto "saber superior" y objetivo, que refuerzan la lógica y los imperativos superyoicos del modelo de acumulación y consumo masivos, contribuyen a la sedimentación discursiva de valores liberal-democráticos vinculados a la percepción de una creciente libertad, autonomía y democratización de los individuos, $y$ fomentan la presencia de un discurso que promueve el temor generalizado a salir del sistema socioeconómico vigente, frente a los costos económicos, sociales y culturales derivados de tal decisión (caos de la devaluación, inflación, o bien ambos, pérdida de los hábitus de consumo).

Es en este mismo marco interpretativo en el que puede entenderse, por ejemplo, que durante la experiencia más radicalizada de aplicación del neoliberalismo en la Argentina, durante el gobierno de Carlos Menem (19891999), existiera un goce derivado de metáforas unarias como las del "1 a 1" (el Régimen de Convertibilidad, que estabilizó económicamente la moneda, mediante la aplicación de una paridad cambiaria fija en un plano de igualdad con la superpotencia imperial, en 1991), el recurrente "hermanos y hermanas", al que apelaba con insistencia el discurso de Menem en cada una de sus alocuciones y las metáforas unarias y aconflictivas de la "aldea global" o la "comunidad internacional", en el marco de la percepción creada de fracaso de otras alternativas políticas. En este caso, se afirma que el goce era primordialmente masoquista, producto de la necesidad perentoria de unificarse $y$ "reconciliarse" socialmente para alcanzar un futuro promisorio de paz, libertad, progreso $y$ felicidad para todos. De la misma forma es como puede interpretarse, además, el plus de goce derivado del discurso hegemónico, que señalaba que la Argentina era "importante" a nivel mundial, que sobre todo, a partir del éxito del Plan de Convertibilidad, era "reconocida" socialmente por su "inédita" inserción internacional al orden global, así como las constantes muestras de apoyo y consentimiento de la "comunidad internacional", entre ellas el Fondo Monetario Internacional (FMI) (que consideraba al país como el "mejor alumno") y de los Estados Unidos (que señalaba a la Argentina como "aliado extra Organización del Tratado Atlántico Norte (OTAN)" y "gran amigo" del gobierno estadounidense). Por último, el discurso liberal-democrático se articulaba con el neoliberal, para insistir en la presencia de un "mundo feliz", basado en mayores márgenes de libertad, democratización y progreso para los individuos, frente a las experiencias previas del Estado que "todo lo absorbía" (peronismo de posguerra), o bien, del "autoritarismo" y la "violencia" de períodos anteriores (Dictaduras militares), así como, su control y limitación sobre las libertades $y$ derechos individuales.

\section{A MODO DE CONCLUSIÓN}

En este artículo se propuso recuperar una serie de categorías clave provenientes de la teoría psicoanalítica lacaniana, para examinar algunas de sus múltiples contribuciones potenciales para el desarrollo y enriquecimiento de la teoría política y social contemporánea, y el análisis sociopolítico crítico. Si bien, atentos al riesgo de psicologismo y 
de una siempre posible sobreinterpretación, entendemos que la extensa obra de Lacan puede brindar incalculables aportes teóricos tendientes al desarrollo y expansión del conocimiento en las ciencias sociales $y$ humanas $y$, específicamente, a la construcción de una teoría y un análisis político más complejo e integral de aquello que se define como lo social. Estas contribuciones, que aquí solo se han esbozado, se encuentran actualmente en cierto auge dentro del denominado pensamiento político posfundacional, en consonancia con las indudables aportaciones provenientes de la obra de Slavoj Zizek, Alain Badiou y más recientemente, de las contribuciones de Ernesto Laclau. Sobre todo, se debe destacar el promisorio intento de articular a la izquierda democrática y el psicoanálisis lacaniano, en una audaz propuesta a favor de una "izquierda lacaniana", desarrollada por Jorge Alemán y Yannis Stavrakakis, desde los campos del psicoanálisis y el análisis sociopolítico, respectivamente. En este trabajo, posicionado en esta línea, se ha colocado el eje en algunas de las principales implicancias que resulta posible derivar del complejo pensamiento lacaniano, para el desarrollo y expansión de la teoría política y social, y el análisis sociopolítico crítico. En ese marco, se examinaron tanto sus posibles implicancias teóricas y epistemológicas, como también algunas de sus derivaciones para el análisis empírico. El objetivo "trascendental" era (y continúa siendo) doble. Por un lado, se espera que estas contribuciones puedan servir de algún modo para enriquecer, y sobre todo para estimular y promover, el diálogo crítico e interdisciplinario tendiente a la formación de un marco teórico-metodológico y epistémico que robustezca a la teoría política y permita incrementar la complejización del análisis político crítico de lo social, en el contexto de una sociedad y una realidad sociocultural y política de por sí muy complejas. Por el otro, esperamos poder contribuir, en parte, al desarrollo de una sociedad más justa, libre, democrática, solidaria, plural y emancipada, siguiendo los postulados normativos de una izquierda lacaniana en defensa explícita de una democracia radicalizada y plural.

\section{BIBLIOGRAFÍA}

Aboy Carlés, Gerardo. "Populismo y democracia en la Argentina contemporánea. Entre el hegemonismo y la refundación". Estudios Sociales 28. Universidad Nacional del Litoral, 2005.

Adorno, Theodor y Horkheimer, Max. Dialéctica del iluminismo. Madrid: Editorial Nacional, 2002.

Alemán, Jorge. "Aproximaciones al problema de la metáfora en el texto L'Etourdit (Lacan: Heidegger)". Cuestiones antifilosóficas en Jacques Lacan. Buenos Aires: Atuel, 1993.

Alemán, Jorge. Para una izquierda lacaniana. Buenos Aires: Grama, 2009.

Álvarez, Alicia. La teoría de los discursos de Jacques Lacan. La formalización del lazo social. Buenos Aires: Letra Viva, 2006.

Austin, John. Cómo hacer cosas con palabras. Barcelona: Paidós, 1998.

Badiou, Alain. ¿Se puede pensar la política?. Buenos Aires: Nueva Visión, 2007.

Bajtín, Mijail. "El problema de los géneros narrativos". Estética de la creación verbal. México: Siglo XXI, 1982.

Barros, Sebastián. "Espectralidad e inestabilidad institucional. Acerca de la ruptura populista”. Estudios Sociales 30. 2006: 145-162.

Basualdo, Eduardo. Concentración y centralización del capital en la Argentina durante la década de los noventa. Buenos Aires: UNQUI, 2000.

Bauman, Zigmunt. En busca de la política. Buenos Aires: FCE, 2003.

Bauman, Zigmunt. Vida de consumo. Buenos Aires: FCE, 2007.

Benveniste, Emile. "El aparato formal de la enunciación”. Problemas de lingüística general. México. Siglo XxI, 1989: 82-91.

Berdiel Rodríguez, Otto. "La declinación social de la imago paterna y su correlato simbólico: ¿sujeto autorreferencial?”. Psikeba 10. En: <http://www.psikeba.com. ar/articulos2/OB_declinacion_imago_ paterna_sujeto_autorreferencial.htm>

Berger, Peter y Luckmann, Thomas. La construcción social de la realidad. Buenos Aires: Amorrortu, 1997. 
Biglieri, Paula. "Las asambleas barriales como síntoma de la democracia representativa argentina". Cacerolazos y asambleas barriales. La crisis de diciembre de 2001 de la Argentina [Tesis Doctoral]. México: Facultad de Ciencias Políticas y Sociales de la Universidad Nacional Autónoma de México, 2006.

Bourdieu, Pierre. Sociología y cultura. México DF: Grijalbo, 1984.

Braunstein, Néstor. El goce. Un concepto lacaniano. Buenos Aires: Siglo XXI, 2006.

Copjec, Joan. El sexo y la eutanasia de la razón. Ensayos sobre el amor y la diferencia. Buenos Aires: Paidós, 2006.

De Saussure, Ferdinand. Curso de lingüística general. Buenos Aires: Losada, 1961.

Derrida, Jacques. La escritura y la diferencia. Barcelona: Anthropos, 1989.

Dor, Joel. Introducción a la lectura de Lacan. Barcelona: Gedisa, 1997.

Fair, Hernán. "El síntoma como formalizador del lazo social. Intersecciones entre psicoanálisis y política (Los Piqueteros)”. Revista de Ciencias Sociales 125 (III). Costa Rica. Editorial de la Universidad de Costa Rica, 2009a: 69-91.

Fair, Hernán. "La elusión del síntoma social del capitalismo contemporáneo”. Utopía y praxis latinoamericana 46 . Universidad del Zulia, 2009b: 83-99.

Fair, Hernán. "Identidades, discurso $y$ política. La articulación y consolidación de la cadena significante menemista en torno al Régimen socioeconómico de la Convertibilidad (1991-1995)". Pléyade 5. Santiago de Chile, 2010a: 83-146.

Fair, Hernán. "Las utopías consensualistas del fin de la política". Revista Mexicana de Ciencias Politicas y Sociales 208. UnAM, 2010b: 15-39.

Fair, Hernán. "Por una economía con un rostro humano. Crítica a la filosofía utilitarista neoliberal a partir del caso argentino". Persona y Sociedad 24. Universidad Alberto Hurtado, 2010c: 69-93.

Foucault, Michel. Vigilar y castigar. Buenos Aires: Siglo XXI, 2003.
Freud, Sigmund. "Psicopatología de la vida cotidiana". Obras completas de Sigmund Freud. Tomo 1. Madrid: Biblioteca Nueva, 1973a.

Freud, Sigmund. "El chiste y su relación con el inconsciente". Obras completas de Sigmund Freud. Tomo 1. Madrid: Biblioteca Nueva, 1973b.

Freud, Sigmund. "Psicología de las masas y análisis del yo". Obras completas de Sigmund Freud. Tomo 3. Madrid: Biblioteca Nueva, 1973c.

Freud, Sigmund. "El malestar en la cultura". Obras Completas de Sigmund Freud. Tomo 3. Madrid: Biblioteca Nueva, $1973 d$.

Freud, Sigmund. "El trabajo del sueño". La interpretación de los sueños. Obras Completas. Tomo 4. Buenos Aires. Amorrortu, 1979: 285-315.

Gómez, Mariana. "La década de los noventa en Argentina. Ideología y subjetividad en la sociedad menemista". Revista Latina de Comunicación Social 61. 2006. En: $<$ http://www.ull.es/publicaciones/ latina/200610gomez.htm10gomez.htm>

Gramsci, Antonio. Notas sobre Maquiavelo, sobre la politica y sobre el Estado moderno. Buenos Aires: Nueva Visión, 1984.

Heidegger, Martin. El ser y el tiempo. Buenos Aires: FCE, 1991.

Jakobson, Roman. "Lingüística y Poética". Ensayos de Lingüística General. Barcelona. Planeta-De Agostini, 1985: 347-394.

Lacan, Jacques. "Lo simbólico, lo imaginario y lo real". Conferencia. Paris: Anfiteatro del Hospital psiquiátrico de Saint Anne, 8 de julio de 1953. Traducción de Ricardo Rodríguez Ponte y compañía, Escuela Freudiana de Buenos Aires (EFBA). Versión crítica. Buenos Aires, 1953.

Lacan, Jacques. Seminario XIX. ...Ou pire. Edición íntegra en español. 1971-1972.

Lacan, Jacques. "Tópica de lo imaginario". Seminario I. Los escritos técnicos de Freud. Buenos Aires: Paidós, 1982. 
Lacan, Jacques. Seminario XI. Los cuatro conceptos fundamentales del psicoanálisis. Buenos Aires: Paidós, 1987a.

Lacan, Jacques. "Kant con Sade". Escritos II. Buenos Aires. Siglo XXI, 1987: 744-770.

Lacan, Jacques. Escritos I. Buenos Aires: Siglo XXI, 2003.

Lacan, Jacques. El triunfo de la religión. Buenos Aires: Paidós, 2005.

Lacan, Jacques. Seminario XVII. El reverso del psicoanálisis. Buenos Aires: Paidós, 2006.

Lacan, Jacques. Seminario XX. Aun. Buenos Aires: Paidós, 2008.

Lacan, Jacques. Seminario XVIII. De un discurso que no fuera del semblante. Buenos Aires: Paidós, 2009.

Laclau, Ernesto y Mouffe, Chantal. Hegemonía y estrategia socialista. Hacia una radicalización de la democracia. Buenos Aires: FCE, 1987.

Laclau, Ernesto. Nuevas reflexiones sobre la revolución de nuestro tiempo. Buenos Aires: Nueva Visión, 1993.

Laclau, Ernesto. "¿Por qué son útiles los significantes vacíos en política?". Emancipación y diferencia. Buenos Aires. Ariel, 1996: 69-86.

Laclau, Ernesto. La razón populista. Buenos Aires: FCE, 2005.

Laclau, Ernesto. "Política de la retórica". Misticismo, retórica y política. Buenos Aires. FCE, 2006: 57-99.

Laclau, Ernesto. Debates y combates. Por un nuevo horizonte de la política. Buenos Aires: FCE, 2008.

Lakoff, George y Johnson, Mark. Metáforas de la vida cotidiana. Madrid: Cátedra, 1998.

Lebrun, Jean Pierre. Un mundo sin límite. Ensayo para una clínica psicoanalítica de lo social. Barcelona: del Serbal, 2003.

Le Guern, Michel. La metáfora y la metonimia. Madrid: Cátedra, 1976.

Lipovetsky, Gilles. "Espacio público y espacio privado en la era posmoderna". El reverso de la diferencia. Identidad y política. Arditi, B. (ed.). Caracas. Nueva Sociedad, 2000: 23-35.
Lyotard, Jean Francoise. La condición postmoderna. Buenos Aires: Amorrortu, 1992.

Marcuse, Herbert. Un ensayo sobre la liberación. México: Joaquín Mortiz, 1983.

Marchart, Oliver. El pensamiento político posfundacional. La diferencia política en Nancy, Lefort, Badiou y Laclau. Buenos Aires: FCE, 2009.

Marx, Karl. El capital. México: Siglo XxI, 1999.

Morin, Edgar. El método IV. Las ideas. Madrid: Cátedra, 1998.

Peirce, Charles. Philosophical writings. Buchler, J. (ed.). New York. Dover Publications, 1955: 74-93.

Ramírez Escobar, Jesús Manuel. "Complemento epistemológico sobre el debate del psicoanálisis con las Tcc". Psikeba. Revista de Psicoanálisis y Estudios Culturales 10. 2009. En: <http:// www. psikeba.com.ar/articulos $2 / \mathrm{JRE}$ psicoanalisis_terapias_cognitivo_\%20 conductuales_complemento _ epistemologico_al_debate_psicoanalisis_ tcc.htm>

Ranciere, Jacques. El desacuerdo. Politica y filosofía. Buenos Aires: Nueva Visión, 1996.

Rome, Natalia. Semiosis y subjetividad. Buenos Aires: Prometeo, 2009.

Rousseau, Jean Jacques. Discurso sobre el origen y los fundamentos de la desigualdad entre los hombres. Madrid: Alianza, 1996.

Sissa, Giulia. El placer y el mal. Filosofía de la droga. Buenos Aires: Manantial, 1968.

Stavrakakis, Yannis. Lacan y lo político. Buenos Aires: Prometeo, 2008.

Stavrakakis, Yannis. La izquierda lacaniana. Buenos Aires: FCE, 2010.

Vainer, Alejandro. "Efectos dogmáticos de Lacan en la Argentina”. Topía 21. Buenos Aires: Facultad de psicología de la UBA, 1997.

Verón, Eliseo. La semiosis social. Buenos Aires: Gedisa, 1987.

Voloshinov, Valentín. El marxismo y la filosofía del lenguaje. Madrid: Alianza Universidad, 1992. 
Wittgenstein, Ludwig (1958). Investigaciones Filosóficas. Barcelona: Crítica, 1988.

Zizek, Slavoj. El sublime objeto de la ideología. Buenos Aires: Siglo XXI, 1992.

Zizek, Slavoj. "Más allá del análisis del discurso". Nuevas reflexiones sobre la revolución de nuestro tiempo. E. Laclau (ed.). Buenos Aires: Nueva Visión, 1993.

Zizek, Slavoj. El espinoso sujeto. El centro ausente de la ontología política. Buenos Aires: Paidós, 2001.
Zizek, Slavoj. "¿Lucha de clases o posmodernismo? ¡Sí, por favor!”. Contingencia, hegemonía $y$ universalidad. Diálogos contemporáneos en la izquierda. Butler, J.; Laclau, E. y Zizek, S. (comps.). México. FCE, 2003: 95-140.

Fecha de ingreso: $22 / 08 / 2011$ Fecha de aprobación: 10/08/2012 
